\title{
The enhancement of operating properties of intumescent fire-protective compositions
}

\author{
Andrey Ustinov ${ }^{1 *}$, Olga Zybina ${ }^{1,2}$, Anastasia Tomakhova ${ }^{1}$, and Sergey Pavlov ${ }^{3}$ \\ ${ }^{1}$ Peter the St. Petersburg Polytechnic University, Polytechnicheskaya 29, St. Petersburg, 195251, \\ Russian Federation \\ 2“Gefest” Enterprise group, 65A Serdobolskaya st., St. Petersburg, 197342, Russian Federation \\ ${ }^{3}$ Ioffe Physical-Technical Institute of the Russian Academy of Sciences, 26 Politekhnicheskaya, St. \\ Petersburg, 194021, Russian Federation
}

\begin{abstract}
The paper overviews the operational properties of charred layers which are forming as a result of thermolytical synthesis of intumescent coatings, and the ways of enhancing those properties using different additives mixed with initial intumescent composition. Methods including differential thermal analysis, thermogravimetric analysis, microscale calorimetry and scanning electron microscopy were used to investigate the modified intumescent compositions and the properties of charred layers formed from them. Results show that additives tend to change the microstructure of char which undergoes some transformations; it is proven by increase in volume and stability. Also it is shown that melamine-aldehyde resin was detected in the microstructure of char, and it is a step forward in forming a holistic conception of intumescents operating.
\end{abstract}

\section{Introduction}

Fireproofing charring compositions are frequently used and well-known: first patents were published in 1930s [1,2]. A significant amount of researches [3-9] which purpose is to improve fire resistance of building constructions and materials shows that the work on enhancing the properties of swelling compositions continues nowadays. As intumescent materials exist for such a long period of time, researchers have found the optimal technological complex for producing intumescent compositions which ensure effective fire protection of constructions and materials. That complex includes few variants of superpositions of ingredients and it's empirical; though some researchers $[10,11]$ try to systemize an experimental data, the clear concept of producing fireproofing charring compositions does not exist. Lack of communication between theory and practice is a problem which hampers the enhancing of intumescent technology and doesn't let to use intumescent compositions more widely.

There are acknowledged statements $[12,13]$ that intumescents which include ammonium polyphosphate (AP), melamine (MA) and pentaerythritol (PE) as basic components undergo physico-chemical transformations when they get heated; those transformations

\footnotetext{
* Corresponding author: au.spbpu@gmail.com
} 
lead to forming a new polymeric structure which gets swelled by gaseous sub-products. Some researchers $[14,15]$ consider ether resin to be that polymer; this resin should form as a result of interaction between PE and AP. But our data provided by IR-spectroscopy, differential thermal analysis, chromatography mass-spectrometry and etc. allows to state that thermolysis of intumescent compositions results in forming of melamine-aldehyde resin [16].

The knowledge about the polymer which serves as a basis of a charred layer allows to consciously choose additives that can help in creating intumescent compositions with improved operational properties. These additives may be strengthening the char's structure (mineral fibers and hollow microspheres) or they can work as active catalysts - for example the carbon nanoclusters which have an impact on thermolysis and the final properties of intumescent layers [17].

Manufacturing of carbon nanomaterials is expensive and laborious, and using them as additives significantly increases the cost of an intumescent material. That is why expensive fullerenes or nanotubes may be replaced by some cheaper materials - graphenes and graphites. Our researches [18] show that graphenes increase operational properties of intumescent coatings when their quantity in composition exceeds 3 mass.\%.

\section{Methods}

To prove the statement of melamine-aldehyde resin being the basis of a charred intumescent layer, the thermolytical synthesis of a resin was conducted using the mixture of melamine and pentaerythritol on ammonium polyphosphate's surface. To do so melamine and pentaerythritol (1:1) were mixed and applied to a layer formed from a molten ammonium polyphosphate (fig. 1).
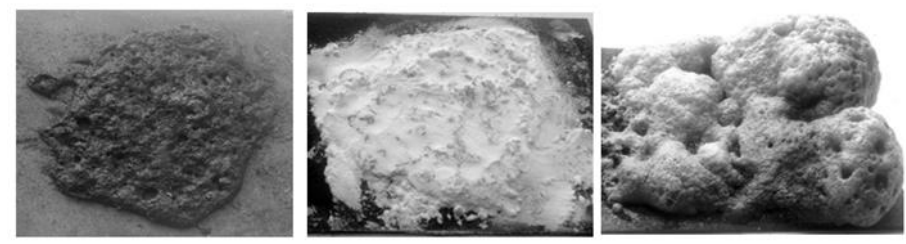

Fig. 1. Stages of thermolytical synthesis of melamine-aldehyde resin from a PE-MA mixture: left ammonium polyphosphate melting; middle - PE-MA mixture applied on AP surface; right - a swollen resin after annealing in a furnace

IR-specters of this product were obtained using Fourier-transform IR-spectrometer IRPrestige-21 (SHIMADZU, Japan) and Fourier-transform IR-microscope AIM-8800 in transmission regime. Fig. 2 shows an area $(150 \times 200 \mu \mathrm{m})$ from which the IR-specter was obtained; specters were the same in other areas of the material.



Fig. 2. An area of melamine-aldehyde resin from which the IR-specter was obtained

The comparison of operational properties of coatings modified with carbon nanoclusters and mineral microspheres was conducted. Previously [19] it was established that 
compositions with microspheres have an increased fire-protective effectiveness (up to 10 min). Swelling coefficient and the amount of time needed for a protected steel plate to reach $500{ }^{\circ} \mathrm{C}$ while annealing in a furnace, were chosen as comparative parameters.

To prove the positive effect of carbon nanoclusters on fire-protective properties of intumescents, the fire tests were conducted according to GOST 53295 methods; specimens contained 0.9 mass. $\%$ of fullerene soot have shown 10 min increase in thermal stability $[20,21]$.

Microscale calorimetry was additionally used to clarify the way of how carbon nanoclusters influence the intumescents. Different carbon additives ( 0.9 mass. $\%$ each) were mixed with the emulsion paint «OSM-1 GEFEST»; those additives were: single-layer carbon nanotubes («NanoTechCenter», Tambov, Russia), thermally expanded graphite METORAS EG 803-95(99), graphene structures SHS-GR made by the method of starch (SHS-Gr_S) and lignin (SHS-Gr_L) carbonization («FACTORIA-LS», Saint-Petersburg, Russia). Parameters of graphene samples are presented in table 1.

Table 1 - Parameters of graphene samples

\begin{tabular}{|c|c|c|}
\hline Parameters & SHS-Gr_L & SHS-Gr_S \\
\hline Amount of graphene layers & $2-5$ & $2-3$ \\
\hline Impurity $(\%)$ & $<1$ & $<1$ \\
\hline Surface area $\left(\mathrm{m}^{2} / \mathrm{g}\right)$ & 200 & $>500$ \\
\hline
\end{tabular}

Specimens of modified intumescents were investigated using microscale calorimeter «MCC-2» (Govmark, Farmingdale, NY, USA) according to ASTM D7309. Specimen ( 5 $\mathrm{mg}$ ) was annealing at constant heat rate $\left(20^{\circ} \mathrm{C} / \mathrm{min}\right)$ in nitrogen atmosphere.

Also the microstructures of char and melamine-aldehyde resin were investigated using scanning electron microscope JSM 7001F (JEOL, Japan).

\section{Results and discussion}

As the heating $\left(350^{\circ} \mathrm{C}\right)$ of PE-MA mixture applied on AP surface started, the synthesis and swelling of the resin started simultaneously. Interaction between releasing gases and resorcinol has shown the presence of aldehydes. Swelling coefficient of a resin was close to the one of the composition based on AP-PE-MA (3:1:1); on the other hand, the mixture of $\mathrm{AP}$ and PE doesn't tend to form a swollen mass.

Fig. 3 represents an IR-specter of the synthesized resin.



Fig. 3. An IR-specter of the synthesized resin: $x$ - wavelength, $\mathrm{sm}^{-1} ; y$ - absorption

There are groups of bands on the specter which characterize melamine-aldehyde resin. Bands at the intervals (1560 and 1450) $\mathrm{sm}^{-1}$ are caused by triazine ring's vibrations; a bond 
at $1630 \mathrm{sm}^{-1}$ is related to $-\mathrm{C}=\mathrm{N}-$ bond vibrations. A bond at $1448 \mathrm{sm}^{-1}$ defines deformational vibrations of $-\mathrm{CH}_{2}-$ bonds. A bond at $1230 \mathrm{sm}^{-1}$ is caused by $\mathrm{C}-\mathrm{N}$ vibrations. A bond at 981 $\mathrm{sm}^{-1}$ is related to $-\mathrm{C}-\mathrm{N}-\mathrm{H}$.

Table 2 represents the results of fire tests of modified intumescent compositions.

Table 2 - Results of fire tests in a furnace

\begin{tabular}{|c|c|c|c|c|}
\hline № & Additive & $\begin{array}{c}\text { Quantity, } \\
\text { mass \% }\end{array}$ & $\begin{array}{c}\text { Swelling } \\
\text { coefficient }\end{array}$ & $\begin{array}{c}\text { Time of reaching } \\
\mathbf{5 0 0} \text { C, min }\end{array}$ \\
\hline 1 & - & - & 33,7 & 10 \\
\hline 2 & Soot $\mathrm{C}_{60}-\mathrm{C}_{70}$ & 0,9 & 43 & 28 \\
\hline 3 & Soot $\mathrm{C}_{60}-\mathrm{C}_{70}$ & 1,5 & 40,6 & 33 \\
\hline 4 & $\mathrm{Fe} @ \mathrm{C}_{60}$ & 0,01 & 41,3 & 37 \\
\hline 5 & $\mathrm{MC}-\mathrm{Al}_{2} \mathrm{O}_{3}$ & 10 & 44,7 & 35 \\
\hline 6 & $\mathrm{CuPc}$ & 10 & 42,6 & 33 \\
\hline 7 & $\mathrm{FePc}$ & 10 & 45,3 & 75 \\
\hline
\end{tabular}

According to the data collected after fire tests, all modified intumescent compositions show a significant increase in operational properties. It should be mentioned that tetraazate tetrabenzoporphyrin complexes with metals (these substances serve as precursors in cabon nanoclusters synthesis) show great effect when added to an intumescent compound. The way of how those additives operate is unclear now and should be deeply investigated, but it's obvious that their presence have an impact on char's structure.

Fig. $4(a-d)$ show the results of microscale calorimetry; they are represented as graphs where heat release rate is a function of temperature. The red line is referred to the initial intumescent composition, and the black one - to the modified composition.

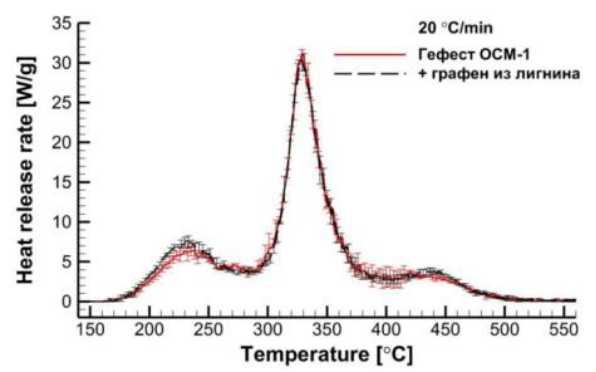

a)

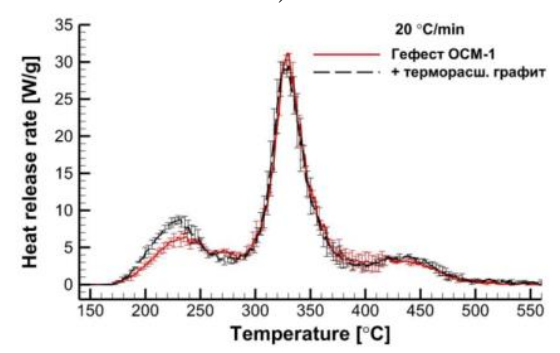

c)

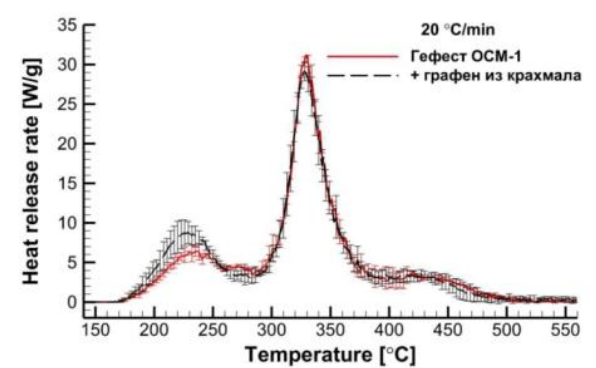

b)



d)

Fig. 4. Results of microscale calorimetry of intumescents modified by: a) graphene $S H S-G r_{-} L, b$ ) graphene $S H S-G r \_S, c$ ) thermally expanded graphite and $d$ ) carbon nanotubes, in comparison with initial composition

Results of microscale calorimetry show that all specimens with carboneus additives undergo a different way of pyrolysis. There is an increase in heat release rate at the 
temperature interval which is referred to polymeric binder's decomposition and pentaerythritol's transformation $\left(170-240^{\circ} \mathrm{C}\right)$, the pikes are also moved to an area of lower temperatures. Increase in heat release rate can be explained by increase in releasing low molecular weighted substances. A pike at about $265^{\circ} \mathrm{C}$ disappears if there are carbo nanoclusters in the system; this temperature is referred to pentaerythritol's decomposition and aldehyde formation, and in case of modified compositions this occurs at lower temperatures. This explains an increase in releasing of gaseous products. Carbon nanoclusters do not affect subsequent stages of pyrolysis according to the collected data.

Fig. $5(a-e)$ represent the microstructure of char formed from initial and modified intumescent compositions.

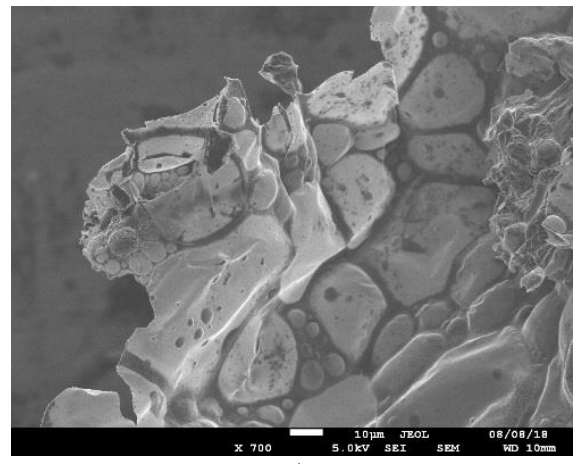

a)

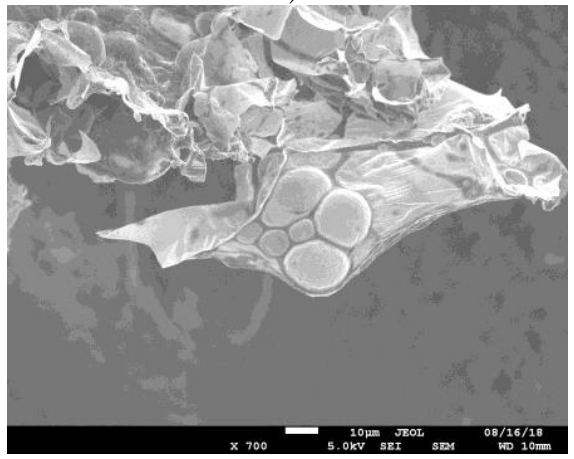

c)

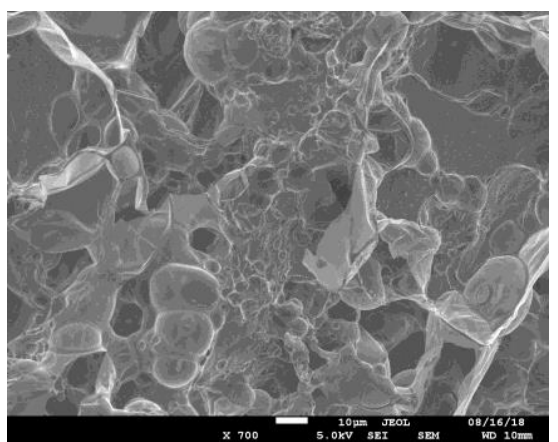

b)



d)



e)

Fig. 5. Microstructure of char pictured using the method of SEM: $a)$ - initial specimen $(\times 700) ; b)-$ specimen with graphene SHS-Gr_S $(\times 700) ; c)$ - specimen with thermally expanded graphite $(\times 700)$; $d)$ - specimen with carbon nanotubes $(\times 700) ; e)$ - specimen with FePc $(\times 700)$

Fig. $6(a, b)$ represent microstructure of melamine-aldehyde resin; specimen was prepared from ME-PE mixture (as was mentioned before). 


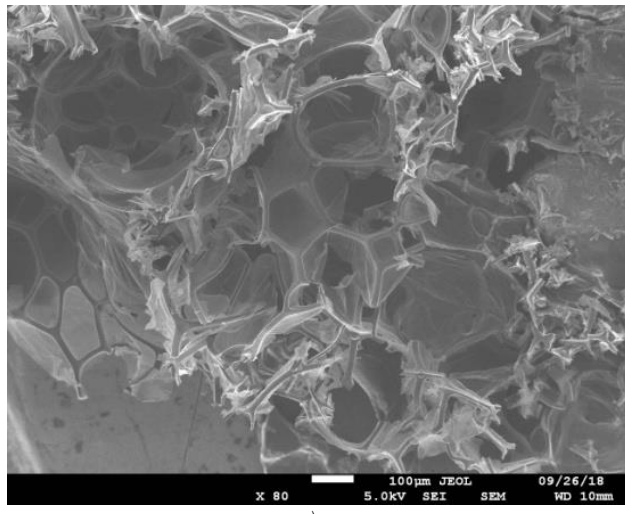

a)

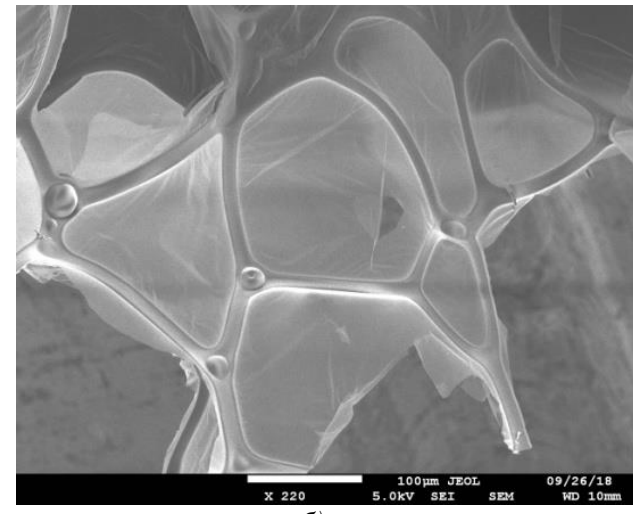

б)

Fig 6. Microstructure of melamine-aldehyde resin: $a) \times 80 ; b) \times 220$

SEM-method allowed to see how different additives may influence the char's microstructure. Adding graphene to an intumescent composition lowers the volume of cells (fig. $5-a, b$ ); this correlates to swelling coefficient's lowering which is detected for specimens with graphene and thermally expanded graphite. Adding carbon nanotubes (fig. 5 $-d$ ) leads to expanding of char's cells thus the swelling coefficient of such coating increases. Adding tetraazate tetrabenzoporphyrin complex with Fe (fig. $5-e$ ) leads to formation of isotropic structure of char, cells got almost equal sizes and seem to be «filled» with gaz; this correlates with the increase in fire-protective properties of such coating.

Microstructures of char formed from AP-ME-PE composition and melamine-aldehyde resin seem to be similar - cells are detected in both cases, but their sizes in resin are significantly bigger. Generally, this collected data allows to say that formation of char in the process of thermolysis of classical intumescents goes through melamine-aldehyde resin forming and swelling by the products of PE decomposition.

\section{Conclusions}

The results of conducted research show that carbon additives may have a significant impact on fire-protective properties of intumescent coatings. Adding fullerene containing soot and endofullerenes increases swelling coefficient by $25-27 \%$ and thermal stability of char up to 18 27 min comparing with an initial specimen. Microadditives also show great effects increasing swelling coefficient and thermal stability of char; an outstanding effect is caused by FePc additive, which increases thermal stability of chat up to 75 min (comparing with 10 min shown by initial specimen).

These effects were explained using microscale calorimetry and scanning electron microscopy. Nano- and microadditives tend to act like catalysts of intumescent process, having impact on thermal decomposition of intumescent components [22-26]. This leads to formation of a more stable and isotropic microstructure of an intumescent layer, which finally leads to increase of it's properies.

Also the research has partially solved an issue about the products of intumescent process. It was proven, using IR-spectroscopy, that melamine-aldehyde resin is a basic polymer which builds the structure of charred layer. This opens a way to a deeper understanding of intumescent process and therefore the enhancing of inrumescent compositions. 


\section{Acknowledgements.}

Authors would like to thank prof. A. Snegirev and his colleagues from «Fluid Dynamics, Combustion and Heat Transfer» department of Peter the Great St. Petersburg Polytechnic University for conducting the microscale calorimetry research.

SEM characterizations were performed using equipment owned by the Federal Joint Research Center «Material science and characterization in advanced technology» with financial support by Ministry of Education and Science of the Russian Federation (id RFMEFI62117X0018).

\section{References}

1. H. M. Spencer, Intumescent silicate compositions. Patent US no. 1847366A (1932)

2. J. W. Olson, Ch. W. Bechle, Bituminous flame resistant compositions and articles coated therewith. Patent US no. 2442707A (1948)

3. O. Zybina, M. Gravit, Y. Stein, IOP Conf. Ser: Earth and Environmental Science, 90(1) (2017)

4. O Nedryshkin, M Gravit, O Mukhamedzhanova, IOP Conference Series: Earth and Environmental Science, 90 (1) (2017)

5. M Gravit, I Dmitriev, A Ishkov, IOP Conference Series: Earth and Environmental Science 90 (1) (2017)

6. M. Gravit, E. Golub, S. Antonov, Magazine of Civil Engineering, 3, 86-94 (2018)

7. M. Gravit, O. Nedryshkin, O. Ogidan, Magazine of Civil Engineering, 1, 38-46 (2018)

8. A. Lucherini, L. Giuliani, G. Jomaas, Fire Safety J., 95, 42-50 (2018)

9. T. Gong, Q. Xie, X. Huang, Fire Safety J., 95, 113-121 (2018)

10. O. Zybina, M. Gravit, A. Pizhurin, IOP Conf. Ser.: Earth and Environmental Science, 90 (1) (2017)

11. R. G. Puri, A. S. Khanna, J. of Coatings Technology and Research, 14, 1-20, (2017)

12. R. B. R. S. Olivera, A. L. Moreno Jr., L. C. M. Vieira, Structures and Materials J. 10, 220-231 (2017)

13. L. Calabrese, F. Bozzoli, G. Bochicchio, B. Tessadri, S. Rainieri, G. Pagliarini, J. of Phys.: Conf. Ser., 547, 012005 (2014)

14. A. Pavlovich, A. Drinberg, L. Mashlyakovsky, LKM-Press, Moscow (2018) (in Russian)

15. H. L. Vandersall, J. of Fire and Flammability, 2, 97-140 (1971)

16. L. Mashlyakovsky, A. Lykov, V. Repkin (1989)

17. P. Ducrocq, S. Duquesne, S. Magnet, Progress in Organic Coating, 57, 430-438 (2006)

18. C-L. Chiang, S-W. Hsu, J. of Polymer Research, 17 (3) (2010)

19. O. Zybina, O. Babkin, Russian Coatings J., 3, 36-39 (2018)

20. M. Gravit, S. Antonov, O. Nedryshkin, E. Nedviga, V. Pershakov, MATEC Web of Conf. 73, 04007 (2016)

21. D. Zavyalov, O. Zybina, S. Mnacakanov, Naukoemkie tekhnologii funkcionalnyh materialov, 70-72 (2014)

22. A. Ustinov, V. Lebedev, D. Orlova, A. Tomahova, I. Virolainen, SPbPU Week of Science, 142-145 (2017)

23. A. Ustinov, R. Gavakhunova, O. Zybina, Modern Fireproof Materials and Technologies, 163-169 (2017) 
24. A. Ustinov, O. Zybina, L. Tanklevsky, V. Lebedev, A. Andreev, E3S Web of Conferences, 33 (2018).

25. M. Gravit, A. Vaititckii, A. Kopytova, O. Zybina, Advances in Intelligent Systems and Computing, 90 (1) (2018)

26. O. Zybina, A. Varlamov, N. Chernova, S. Mnacakanov, J. of Applied Chemistry, 4, 1445-1449 (2009) 